\title{
Analysis of Resource use Efficiency in Apple Production on Outer Himalayan Range of Chenab Valley
}

\author{
Jahangir Ali*, Jyoti Kachroo, Deep Ji Bhat, S.E.H. Rizvi, B.C. Sharma and \\ Sudhakar Dwivedi
}

Division of Agricultural Economics and ABM, Sher-e-kashmir University of Agricultural Sciences and Technology Jammu, Chatha-180009, India

"Corresponding author: jahangirdar64@gmail.com

\begin{abstract}
The present study was carried out in the Jammu region of Jammu and Kashmir state with special emphasis on selected districts viz., Doda, Kishtwar and Rambam, as these regions had the highest area and production under apple crop. Both primary as well as secondary data has been used as per requirements of the study. A multistage sampling technique had been used for the present study. To study the functional relationship between yield of apple and the selected independent variables, Cobb Douglas type of production function in log linear form had been fitted to the collected data for marginal farms, small farms, medium farms and on all the farms put together. The analysis had shown that the co-efficient of determination $\left(\mathrm{R}^{2}\right)$ indicated that 68.3 per cent, 71.2 per cent, 73.7 per cent and 75.5 per cent of the variations in the output of apple had been explained by the six independent variables included in the production function for the marginal, for the Small, for the medium and for the overall sample apple growers respectively. The analysis had also revealed that the sum of the production elasticities for the marginal farmers was 1.403, for the small farmers was 1.57, for the medium farmers was 2.53 and for all sample farmers put together it was 1.989 which showed operation of increasing return to for all categories of apple farmers. Increasing trend in returns to scale of apple suggested the planners to plan strategies for long run so as to safeguard the interest of apple growers involved in the production process.
\end{abstract}

Keywords: Cobb Douglas, production, apple, resources, growers, Jammu

Apples in India are mainly grown in three mountainous states of North India viz. Jammu and Kashmir, Himachal Pradesh and Uttaranchal at an altitude of 4000 to 11000 feet. Jammu and Kashmir and Himachal Pradesh have roughly equal area planted to apple, but J\&K has the highest average yield and accounts 67 per cent of total apple production. Jammu and Kashmir State being endowed with the natural advantage of topography, climate and enormous diversity of agro-climatic niches has immense scope for horticultural development. The apple cultivation in Jammu and Kashmir is an old age activity and originally around 200 varieties of apple used to be cultivated in the state. Reports indicate a productivity of 13.07 metric tonnes per hectare in Kashmir which is the highest in India and is comparable to China. The horticulture sector in the state contributed ₹ 5000 crores towards state gross domestic product during 2013-14 of which apple alone accounted for about ₹ 4000 crores (Naqash, 2017).

The various fruits are grown in India and are exported to different countries in the world. However, apple production is the most prominent one in India. In India apples are grown as a commercial crop in the hilly areas. The apple fruit grows especially in the state of J\&K. Apple production is one of the important sources of revenue for the economy in J\&K. Apple cultivation in $\mathrm{J} \& \mathrm{~K}$ is fast expanding because apple has a comparative advantage over the other crops that can be grown in hilly regions (Bhat and Choure, 2014). Jammu and Kashmir is the major producer 
of apple and walnuts in India, 77 per cent of apple and 90 per cent of walnut production in India belongs to Jammu and Kashmir and percentage share of state in India's total production is showing an increasing trend, so much so that the state has been declared as the "Agri. Export zone for Apples and Walnuts" (Rather et al. 2013). There are around 7 lakh families comprising of about 33 lakh people which are directly or indirectly associated with horticulture. Horticulture development is one of the thrust area and a number of programmes have been implemented in the past, resulting in the generation of higher incomes in the rural areas, thereby improving the quality of life in villages (Islam and Shrivastava, 2017).

\section{MATERIAL AND METHODS}

The present study was carried out in the Jammu region of Jammu and Kashmir state with special emphasis on selected districts viz., Doda, Kishtwar and Rambam, as these regions had the highest area and production under apple crop. These regions fall under Chenab Valley, which are mostly hilly terrain. Chenab Valley lies between the middle and outer Himalayan range in the Jammu region of Jammu and Kashmir, India. Besides that, these three districts have amicable temperature for apple cultivation. Both primary as well as secondary data has been used as per requirements of the study. A multistage sampling technique had been used for the present study.

In order to study relationship between output and various input used, Cobb Douglas production was used. This Function is used extensively in agricultural Production function analysis. The functional form applies is given as under:

$$
Y_{t}=\alpha\left(\prod_{i=1}^{n} X i^{\beta i}\right) u_{t}(t=1,2,3, \ldots \ldots, n)
$$

Where $Y$ and $X_{i}(\mathrm{i}=1,2,3, \ldots \ldots, n)$ are the output and levels of inputs. The constant $\alpha$ and $\beta_{\mathrm{i}}^{\prime}$ s $(i=$ $1,2,3, \ldots \ldots, 6)$ represent the efficiency parameters and the production elasticities of the respective input variables for the given population at a particular period, $t$.

$\mathrm{U}=$ Error term (Assumed to be normally distributed with constant variance and zero mean)

$\beta_{1^{\prime}}, \beta_{2^{\prime}}, \beta_{3^{\prime}} \ldots, \beta_{6}$ are the parameters to be estimated $\alpha=$ Regression constant

On taking log transformation, above function can be transformed to a linear form as:

$\log y=\log \alpha+\beta_{1} \log x_{1}+\beta_{2} \log x_{2}+\beta_{3} \log x_{3}+\beta_{4} \log$ $x_{4}+\beta_{5} \log x_{5}+\beta_{6} \log x_{6}+\log u$

Or $\log y=\alpha+\sum_{i=1}^{6} \beta i \log X_{i}+\log u$

Using ordinary least square technique, the fitted Cobb-Douglas Production may be written for the present case with six input variables as:

$\hat{Y}=\alpha x_{1}^{\beta 1} x_{2}{ }^{\beta 2} x_{3}{ }^{\beta 3} x_{4}{ }^{\beta 4} x_{5}{ }^{\beta 5} x_{6}{ }^{\beta 6}$

Where,

$y=$ Estimated Output (quintals per acre)

$x_{1}=$ Human Labour (man days per acre)

$x_{2}=$ Manures and Fertilizers ( $₹$ per acre)

$x_{3}=$ Expenditure on training and pruning $(₹$ per acre)

$x_{4}=$ Cost of Plant protection measures ( $₹$ per acre)

$x_{5}=$ Cost of irrigation ( $₹$ per acre)

$x_{6}=$ No. of apple trees per acre

The Marginal Value Productivity of the resources and the costs of those resources would give us an indication about the reallocation of the resources to maximize the returns. The optimization principle in respect of resource allocation will suggest that the application of a resource should be increased till the Marginal Value Product (MVP) of a factor will be equal to its marginal cost.

In the present study, the marginal value product of the inputs $x_{1}, x_{2}, x_{3} \ldots \ldots, x_{6}$ was calculated by using the following formula:

$$
M V P j=b i \frac{G M(Y)}{G M(x i)} \times P y
$$

Where,

$M V P_{j}=$ marginal value product for input $x_{i}$

$b i=$ estimated elasticity co-efficient of variable $x_{i}$ $G M(Y)=$ geometric mean yield (quintals per acre) $G M\left(X_{i}\right)=$ geometric mean value of variable $x_{i}(₹ /$ man days /per acre)

$P_{y}=$ Mean net selling price of Apple (₹/quintals) for $j=1,2,3 \ldots, 6$. 


\section{RESULTS AND DISCUSSION}

\section{Resource use efficiency}

To study the functional relationship between yield of apple and the selected independent variables, Cobb Douglas type of production function in log linear form had been fitted to the collected data for marginal farms, small farms, medium farms and on all the farms put together. For analysing the resource use efficiency of various factors, gross product has been taken as dependent variable with labour, manures and fertilizers, PPC, irrigation, training and pruning and number of apple trees as the independent variables. The choice of the best equation was made on the basis of $\mathrm{R}^{2}$ explained and the relevance of the expected sign of coefficients. The marginal value productivity (MVP) of the resources used was worked out with the help of regression coefficients obtained. MVP of a particular resource represents the expected addition to the gross return caused by the additional one unit of the resource input while the other inputs are held constant.

\section{Resource use efficiency in marginal farms}

It could be observed from the Table 1 that with regard to marginal farmers, the coefficient of determination $\left(\mathrm{R}^{2}\right)$ value was found to be .68 which had indicated that 68 per cent of the variations in the output had been explained by the six explanatory variables included in the model. The value of $\mathrm{R}^{2}$ was reasonably high given the obvious fact that there are other explanatory variables such as climate changes, experience of farmers and the managerial abilities of farmers etc. The F-test had shown that the estimated Cobb Douglas type of production function was statistically significant at the one per cent level, implying that all the inputs used in apple production by marginal farmers jointly contribute to the yield of apple. The regression constant had a positive value and it was statistically found to be significant at one per cent level, revealing that the error of approximation of the functional form was significant.

The functional analysis for apple production revealed that $\mathrm{PPC}$, training and pruning and number of apple trees were positively significant at one per cent level. It could be inferred that a one per cent increase in the value of these variables keeping all other factors constant would increase the yield by 0.263 per cent, 0.364 per cent and 0.886 per cent, respectively from their mean level. The elasticity coefficient for the variable cost of irrigation was found to be .103 which had indicated that by increasing the expenditure on irrigation by one per cent, there would be an increase in the yield of apple by 0.103 per cent, Ceteris Paribus. The table 4.22 further revealed that the elasticity coefficient for manures and fertilizers worked out to be -.192 indicating negative relationship with the yield and was significant at 5 per cent level indicated that one per cent increase in the value of manures and fertilizers could decrease the yield by 0.192 per cent from its mean level. However, labour turned out to

Table 1: Estimated Production function for marginal farm

\begin{tabular}{clccccc}
\hline S1. No. & Variables & Notation & Elasticity Co-efficient & Standard Error & t- value & MVP \\
\hline 1 & Intercept & $\mathrm{Y}$ & 16.619 & 2.902 & $5.727^{*}$ & \\
2 & Labour & $\mathrm{X}_{1}$ & -.021 & .046 & $-.456^{\text {NS }}$ & -25.837 \\
3 & Manures and Fertilizers & $\mathrm{X}_{2}$ & -.192 & .054 & $-3.544^{* *}$ & -15.155 \\
4 & PPC & $\mathrm{X}_{3}$ & .263 & .012 & $21.299^{*}$ & 78.201 \\
5 & Irrigation & $\mathrm{X}_{4}$ & .103 & .027 & $3.846^{* *}$ & 16.881 \\
6 & Training and Pruning & $\mathrm{X}_{5}$ & .364 & .013 & $28.685^{*}$ & 41.089 \\
7 & No. of Apple Trees & $\mathrm{X}_{6}$ & .886 & 1.376 & $5.731^{*}$ & 295.605 \\
\hline 8 & $\mathrm{R}^{2}=.683$ & & & & & \\
9 & Adjusted $\mathrm{R}^{2}=.655$ & & & & & \\
10 & F Value $=89.24^{*}$ & & & & & \\
11 & Sum of elasticity coefficients $=1.403$ & & & & & \\
\hline
\end{tabular}

Note: Significant at ${ }^{*} 1$ per cent, ${ }^{* *} 5$ per cent, ${ }^{* * *} 10$ per cent $\mathcal{E}$ NS=Non significant. 
be non-significant variable with elasticity coefficient -0.021 on marginal farms.

The marginal value productivity of irrigation, PPC, training and pruning and number of apple trees were found to be ₹ 16.881, ₹ 78.201, ₹ 41.089 and $₹ 295.605$, respectively and a comparison of MVP of expenditure on irrigation, PPC, training and pruning and number of apple trees with their respective acquisition costs indicated that the MVP of the same were significantly higher than their respective acquisition costs, indicating that there is a scope to increase apple by increasing expenditure on irrigation, PPC, training and pruning and number of apple trees. Alternatively implying that these inputs were used less than their optimal levels. Further, the marginal value productivity of manures and fertilizers had been found to be ₹ -15.155 which was significantly lower than its acquisition cost, implying that the manures and fertilizers were in excessive use and a comparison of MVP of the variable suggest that the yield of apple can be increased by decreasing the use of manures and fertilizers. It could also be observed from the table that sum of elasticities coefficients was estimated to be 1.403, which had indicated the operation of the increasing returns to scale.

\section{Resource use efficiency in small farms}

The details of production function estimates estimated had been presented in the Table 2. The $\mathrm{R}^{2}$ value was .71 which indicated that 71 per cent of the variations in the yield of small apple farms was explained by the explanatory variables viz included labour, manures and fertilizers, PPC, irrigation, training and pruning and number of apple trees in the model. The F value of $39.44 \mathrm{had}$ shown that the estimated Cobb Douglas type of production function was statistically significant at the one percent level, implying that all the inputs used in apple production by small farmers jointly contribute to the yield of apple. It could also be observed from the table that sum of elasticities coefficients was estimated to be 1.57 , which had indicated the operation of the increasing returns to scale on the small farms. Among the independent variables manures and fertilizers, PPC, irrigation, training and pruning and number of apple trees had been found statistically significant. The functional analysis for apple production revealed that manures and fertilizers and training and pruning were positively significant at 5 per cent level indicating that one per cent increase in these variables would increase output by 1.042 per cent and 0.298 per cent, respectively whereas irrigation was positively significant at 10 percent level indicated that one per cent increase in irrigation would increase output by 1.734 per cent. The table also indicated that the regression coefficients of PPC and number of apple trees was found to be negative and production elasticities of the same indicates that one percent increase in PPC and number of apple trees is expected to decrease the yield by -0.321 per cent and -1.365 per cent, respectively indicating negative relationship with the yield and had been found significant at 5 per cent and 10 per cent level, respectively. However labour turned out to be nonsignificant variable with elasticity coefficient -0.131

Table 2: Estimated Production function for small farm

\begin{tabular}{clccccc}
\hline S1. No. & Variables & Notation & Elasticity Co-efficient & Standard error & t-value & MVP \\
\hline 1 & Intercept & $\mathrm{Y}$ & 20.332 & 13.462 & $1.510^{\text {Ns }}$ & \\
2 & Labour & $\mathrm{X}_{1}$ & -.131 & .130 & $-1.012^{\text {NS }}$ & -545.216 \\
3 & Manures and Fertilizers & $\mathrm{X}_{2}$ & 1.042 & .700 & $2.915^{* *}$ & 562.405 \\
4 & PPC & $\mathrm{X}_{3}$ & -.321 & .088 & $-3.651^{* *}$ & -174.668 \\
5 & Irrigation & $\mathrm{X}_{4}$ & 1.734 & .799 & $2.170^{* * *}$ & 838.166 \\
6 & Training and Pruning & $\mathrm{X}_{5}$ & .298 & .061 & $4.887^{* *}$ & 120.826 \\
7 & No. of Apple Trees & $\mathrm{X}_{6}$ & -1.365 & 6.077 & $-2.199^{* * *}$ & -1153.88 \\
\hline 8 & $\mathrm{R}^{2}=.712$ & & & & \\
9 & Adjusted $\mathrm{R}^{2}=.695$ & & & & & \\
10 & F Value $=39.441^{*}$ & & & & & \\
11 & Sum of elasticity coefficients $=1.57$ & & & & & \\
\hline
\end{tabular}

Note: Significant at ${ }^{*} 1$ per cent, ${ }^{* *} 5$ per cent, ${ }^{* * *} 10$ per cent $\mathcal{E}$ NS=Non significant. 
on small farms. The marginal value productivity of only those resources had been discussed, whose coefficients were found to be influencing the yield of apple production significantly. The MVP of manures and fertilizers, irrigation and training and pruning had been found positive with their values ₹ 562.40, ₹ 838.16 and ₹ 120.82 , respectively and a comparison of acquisition costs with their MVP showed that the MVP of manures and fertilizers and irrigation was significantly higher than their acquisition cost, implying that the inputs viz manures + fertilizers and irrigation were sub optimally used and yield of apple can be increased by increasing the level of manures + fertilizers and irrigation. However MVP of training and pruning was less than its price i.e. wage rate, whereas MVP for PPC and number of apple trees had been found negative with their values $₹-174.668$ and $₹-1153.88$, respectively, which was significantly lower than its acquisition cost, implying that the PPC and number of apple trees in apple production were in excessive use and a comparison of MVP of the variables suggested that the yield of apple can be increased by decreasing the use of PPC and number of apple trees.

\section{Resource use efficiency in medium farms}

Multiple regression analysis of data was done through Cobb Douglas production function which was the best fitted model with highest $\mathrm{R}^{2}$ (73 per cent). The data in the Table 3 explores the resource use efficiency in apple production on medium farms. The F value (37.13) had shown that the estimated Cobb Douglas type of production function was statistically significant at the one per cent level of probability. The functional analysis for apple production on medium farms indicated that one per cent increase in use of labour, manures + fertilizers is expected to increase the apple production by 0.298 per cent and 0.342 per cent, respectively and had been positively significant at 10 per cent level, whereas PPC and training and pruning was positively significant at 1 per cent level which indicated that one percent increase in PPC and training and pruning could increase 0.164 per cent and 0.232 per cent, respectively. The table further revealed that the inputs such as irrigation and number of apple trees were statistically non-significant variables on marginal farms. The marginal value productivity of labour (₹ 1000.827) and number of apple trees (₹ 1394.45) exercised a positive impact on yield and comparison of acquisition cost (price) with its MVP showed that MVP labour and number of apple trees were significantly higher than the acquisition cost, implying that the inputs labour and number of apple trees were sub-optimally used and yield of apple can be increased by increasing the level of same inputs. However, MVP of inputs viz manures + fertilizers, PPC, training and pruning and had been found less that their acquisition cost (price) with their values ₹ 72.367, ₹ 124.792 , ₹ 70.518 and, respectively. The nature of elasticity coefficients was positive and was estimated to be 2.53 , which had indicated the operation of the increasing returns to scale.

Table 3: Estimated Production function for medium farm

\begin{tabular}{clccccc}
\hline S1. No. & Variables & Notation & Elasticity Co-efficient & Standard error & t-value & MVP \\
\hline 1 & Intercept & $\mathrm{Y}$ & 10.519 & 8.520 & $1.235^{\text {Ns }}$ & \\
2 & Labour & $\mathrm{X}_{1}$ & .298 & .139 & $2.152^{* * *}$ & 1000.827 \\
3 & Manures and & $\mathrm{X}_{2}$ & .342 & .158 & $2.167^{* * *}$ & 72.367 \\
& Fertilizers & $\mathrm{X}_{3}$ & .164 & .034 & $4.815^{*}$ & 124.792 \\
4 & PPC & $\mathrm{X}_{4}$ & -.008 & .101 & $-.080^{\text {NS }}$ & -3.243 \\
5 & Irrigation & $\mathrm{X}_{5}$ & .232 & .031 & $7.390^{*}$ & 70.518 \\
6 & Training and Pruning & $\mathrm{X}_{6}$ & 1.509 & 4.053 & $1.359^{\text {NS }}$ & 1394.45 \\
7 & No. of Apple Trees & & & & & \\
8 & $\mathrm{R}^{2}=.737$ & & & & \\
9 & Adjusted $\mathrm{R}^{2}=.715$ & & & & & \\
10 & F Value $=37.136^{*}$ & & & & & \\
11 & Sum of elasticity coefficients $=2.53$ & & & &
\end{tabular}

Note: Significant at ${ }^{*} 1$ per cent, ${ }^{* *} 5$ per cent, ${ }^{* * *} 10$ per cent $\mathcal{E}$ NS=Non significant. 


\section{Resource use efficiency in all farms}

Estimates of a Cobb Douglas type of production function are presented in the Table 4 . The results revealed that the model was good fit on the basis of coefficient of determination. Since it could explain 75 per cent of the variations in the output of all farms together (overall). The $\mathrm{F}$ value of 54.980 had shown that the fitted Cobb Douglas type of production function was statistically significant at the one percent level of probability. Among the independent variables manures and fertilizers, PPC and training and pruning had been found statistically significant. The functional analysis for apple production revealed that an increase of one per cent in manures and fertilizers, PPC and training and pruning can increase apple production by 0.69 per cent, 0.23 per cent and 0.21 per cent, respectively. It could also be seen from the table that the elasticity coefficient for labour, irrigation and number of apple trees indicated that, an increase in one per cent of these inputs could increase output by 0.002 per cent, 0.009 per cent and 0.835 percent, respectively and had been found statistically nonsignificant. It is evident from the table 4.25 that production elasticities for all inputs were below unity, implying that increasing the respective inputs by one percent would increase apple production by less than one per cent. Conversely, the return to scale parameter was found to be 1.989 which has indicated the operation of the increasing returns to scale on all farms together. Farmers were still operating in irrational Stage I of the production function, where the inputs employed were not efficiently utilized which can be attributed to intercroping pulses, maize and vegetables and not using recommended dosage of fertlizers, manures and PPC to control apple diseases. Similar findings were reported by Ainembabazi et al. (2005), Gowa et al. (2001), and Paris and Caputo (2004), Ogundari and Ojo (2007) and Ntakyo et al. (2013).

This means that efficient utilisation of inputs through better management options will be key to increasing output in apple production. The marginal value productivity of labour, manures and fertilizers, PPC, irrigation and training and pruning and number of apple trees had been found positive with their values ₹ 5.48 , ₹ 122.76 , ₹ 122.36 , $₹ 3.05$, ₹ 54.40 and $₹ 571.40$ respectively. Since all productivities were positive, thus exhibiting the production function property of monotonicity. The inputs with the highest marginal productivities had been number of apple trees followed by manures and fertilizers, PPC, training and pruning, labour and irrigation.

However, the MVP suggested that it was not advisable to increase labour, labour, manures and fertilizers, PPC, irrigation and training and pruning in apple cultivation. This could be due to the fact that it was not cost effective to add more of these inputs because their marginal value product had been below their marginal input costs. Also it can be attributed that some of the trees were still in a growing stage and had not reached peak production, thus depicting low productivity in labour and other variables. This is consistent with previous studies of Bagamba et al. (2007) and Okoboi (2010) which

Table 4: Estimated Production function for all farms

\begin{tabular}{clccccc}
\hline S1. No. & Variables & Notation & Elasticity Co-efficient & Standard error & t-value & MVP \\
\hline 1 & Intercept & $\mathrm{Y}$ & -6.717 & 15.230 & $-.441^{\text {NS }}$ & \\
2 & Labour & $\mathrm{X}_{1}$ & .002 & .192 & $.010^{\text {NS }}$ & 5.48 \\
3 & Manures and Fertilizers & $\mathrm{X}_{2}$ & .697 & .235 & $2.969^{* *}$ & 122.76 \\
4 & PPC & $\mathrm{X}_{3}$ & .232 & .056 & $4.137^{* *}$ & 122.36 \\
5 & Irrigation & $\mathrm{X}_{4}$ & .009 & .148 & $.064^{\text {NS }}$ & 3.05 \\
6 & Training and Pruning & $\mathrm{X}_{5}$ & .214 & .055 & $3.859^{* *}$ & 54.40 \\
7 & No. of Apple Trees & $\mathrm{X}_{6}$ & .835 & 5.732 & $.320^{\text {NS }}$ & 571.40 \\
\hline 8 & $\mathrm{R}^{2}=.755$ & & & & & \\
9 & Adjusted $\mathrm{R}^{2}=.725$ & & & & & \\
10 & F Value= $54.980^{*}$ & & & & & \\
11 & Sum of elasticity coefficients $=1.989$ & & & & & \\
\hline
\end{tabular}

Note: Significant at ${ }^{*} 1$ per cent, ${ }^{* *} 5$ per cent, ${ }^{* *} 10$ per cent $\mathcal{E}$ NS=Non significant. 
reported low marginal returns to investment in Uganda.

\section{Multicollinearity}

Multicollinearity explains the linear relationship among the independent variables of the regression model. Multicollinearity statistics of data as expressed in tolerance and variance inflation factor showed in the Table 5 revealed that the values of tolerance for all explanatory variables viz $\left(X_{1^{\prime}}\right.$ labour $),\left(X_{2^{\prime}}\right.$ manures and fertilizers $),\left(X_{3^{\prime}}, P P C\right),\left(X_{4^{\prime}}\right.$ irrigation $)$ and $\left(X_{5^{\prime}}\right.$ training and pruning) and $\left(X_{6}\right.$ number of apple trees) lied in the range of 0.157 to 0.68 which had been somewhat closer to zero and had implied that there was no serious collinearity among the explanatory variables. On the other hand the values of variance inflating factor were less than 10 ranging between 1.46 to 6.33 indicating that there was no collinearity among all the explanatory variables included in the model.

Table 5: Multicollinearity statistics of overall farms

\begin{tabular}{ccccccc}
\hline $\begin{array}{c}\text { Collinearity } \\
\text { statistics }\end{array}$ & $\mathbf{X}_{1}$ & $\mathbf{X}_{2}$ & $\mathbf{X}_{3}$ & $\mathbf{X}_{4}$ & $\mathbf{X}_{5}$ & $\mathbf{X}_{6}$ \\
\hline Tolerance & .219 & .334 & .491 & .591 & .157 & .681 \\
VIF & 4.558 & 2.995 & 2.036 & 1.691 & 6.338 & 1.468 \\
\hline
\end{tabular}

Based on the findings of the study, the following necessary steps could be made for the improvement and development of the apple production in the study area.

Classes at mass scale should be conducted by various horticulture departments and institutions in fruit growing areas, where apple growers should be informed about the latest horticulture technology. For this purpose demonstration plots should be set up in fruit producing areas. Further, the education with respect to orchard management practices is of pertinent importance and should also be imbued among the farmers.

A rigorous advertisement campaign should be launched to inform growers about the proper use of resources and their relative benefits, the government had to take efforts through the department of horticulture for the efficient use of the resources by the apple growers so that they could maximize their returns.

To meet the present requirement of irrigation all methods of irrigation i.e., ditches, storage ponds and drip irrigation etc. should be developed and extended. Merely by extended application of one particular method of irrigation cannot meet the requirement and demands of irrigation.

\section{CONCLUSION}

Apple had been a major cash crop in the study area, despite long years of cultivation apple production and productivity was very low and has been concentrated in fewer pockets of the selected districts. The area coverage is still far below from the available potential. To realize the scope for further increases in the net returns per acre, the resource use efficiency was analysed. The CobbDouglas type of production function was fitted to evaluate the resource productivity and the returns to scale in apple cultivation. The analysis had shown that the co-efficient of determination $\left(\mathrm{R}^{2}\right)$ indicated that 68.3 per cent, 71.2 per cent, 73.7 per cent and 75.5 per cent of the variations in the output of apple had been explained by the six independent variables included in the production function for the marginal, for the Small, for the medium and for the overall sample apple growers respectively. Among the independent variables, the expenditure on manures and fertilizers, plant protection chemicals and costs on training and pruning had been found to be significant at the five per cent level for overall farmers. The analysis had also revealed that the sum of the production elasticities for the marginal farmers was 1.403, for the small farmers was 1.57, for the medium farmers was 2.53 and for all sample farmers put together it was 1.989 which showed operation of increasing return to for all categories of apple farmers. Increasing trend in returns to scale of apple suggested the planners to plan strategies for long run so as to safeguard the interest of apple growers involved in the production process.

\section{REFERENCES}

Naqash, F. 2017. Value chain Analysis of apple in Kashmir valley of J and K state. M.Sc. (Agri.) Thesis, Sher e Kashmir University of Agricultural Science and Technology, Kashmir, (India).

Islam, R.T. and Shrivastava, S. 2017. A Study on Area, Production and Productivity of Apples in J\&K from 200607 to 2015-16. International Journal of Scientific Research and Management, 5(07): 6513-6519.

Rather, N.A., Lone, P.A., Reshi, A.A. and Mir, M.M. 2013. An Analytical Study on Production and Export of Fresh and 
Dry Fruits in Jammu and Kashmir. International Journal of Scientific and Research Publications, 3(2):1-7.

Bhat, T.M. and Choure, T. 2014. Status and Strength of Apple Industry in Jammu and Kashmir. International Journal of Research, 1(4): 277-283.

Ainembabazi, J., Bashaasha, B., Mugisha, J. Pender, J. and Hyuha, T.S. 2005. Technological change in sorghum production in Eastern Uganda. African Crop Science Conference Proceedings, 7: 947 -954.

Gowa, A.K., Bashasha, B. and Tayebwa, B. 2001. Determination of optimal levels of resource use in clonal robusta coffee production in central Uganda. Eastern Africa Journal of Rural Development, 17(1): 1-8.

Paris, Q. and Caputo, R.M. 2004. A primal-dual estimator of production and cost functions with an error-in-variables context. Department of Agricultural and Resource Economics, University of Carifornia, Davis, 4(8).
Ntakyo, P.R., Mugisha, J. and Elepu, G. 2013. Socio-Economic Factors Affecting Apple Production in Southwestern Uganda. African Crop Science Journal, 21(4): 311-321.

Ogundari, K. and Ojo, S. 2007. Economic efficiency of small scale food crop production in Nigeria: a stochastic frontier approach. Journal of Social Sciences, 14(2): 123-130.

Okoboi, G. 2010. Improved input use and productivity in Uganda's maize sub-sector. Kampala, Uganda. .Economic Policy and Research Center, 69.

Bagamba, F., Burger, K., Ruben, R. and Kuyvenhoven, A. 2007. Market access, agricultural productivity and allocative efficiency in the banana sector of Uganda. $C A B$ International. 301. 